\title{
A emancipação da mulher na imprensa feminista nos primeiros anos da República no Brasil
}

Marta de Souza Rodrigues e

Artur Alves da Silva

\section{Resumo:}

A luta das mulheres para obtenção de direitos humanos, sociais e civis, realizada a partir de múltiplas estratégias em diferentes momentos históricos, ampliou a participação feminina na sociedade brasileira e permanece reivindicando a concretização de direitos garantidos pelo texto constitucional. Durante o século XIX, uma parte dos jornais e periódicos se destinava aos interesses femininos e, dentre eles, a imprensa feminista exerceu o importante papel de fomentar discussões que questionavam a posição da mulher na sociedade em defesa da emancipação feminina - ora entendida como a ampliação da participação das mulheres na esfera pública, ora como a igualdade de direitos entre mulheres e homens. Este artigo tem por objetivo investigar o conceito de emancipação feminina nos primeiros anos da República presente nos jornais A Família e O Quinze de Novembro do Sexo Feminino, importantes representantes das perspectivas acerca do papel das mulheres na sociedade brasileira. Palavras-chave: Direitos Civis - Movimentos de Mulheres - Imprensa Feminista - Emancipação Feminina 
A emancipação da mulher na imprensa feminista nos primeiros anos da República no Brasil

A militância das mulheres brasileiras, atualmente, se destaca como um dos setores sociais de maior participação no espaço público quando o assunto é a reivindicação da universalização de direitos humanos, sociais e civis, garantidos pela constituição a toda a população brasileira. A ampliação de direitos e oportunidades na vida pública coexiste, no entanto, com preconceitos e estereótipos sobre as mulheres que permanecem no imaginário coletivo, ameaçando a efetivação de conquistas sociais, como o direito à educação, ao trabalho profissional e à participação política. Nota-se esta desigualdade ao se observar que as mulheres ainda são minoria entre os representantes eleitos pelo povo, recebendo remunerações inferiores em comparação aos homens e sendo menos reconhecidas historicamente, o que se pode perceber ao analisar a masculinização dos heróis do país no currículo escolar.

Por meio de diversas manifestações sociais, como passeatas, eventos acadêmicos, estudos científicos, publicações de livros e veiculação de matérias jornalísticas impressas e pela internet, é possível perceber a agência social das mulheres na luta pelo exercício efetivo da igualdade de direitos entre os sexos feminino e masculino. Dentre alguns dos principais instrumentos de discussão e reivindicação, utilizados desde meados do século XIX, está a imprensa feminista. Neste sentido, os jornais $O$ Quinze de Novembro do Sexo Feminino e A Família se destacaram como publicações feministas de grande importância histórica, responsáveis por abordar, debater e divulgar a questão da emancipação da mulher como parte da vida pública nacional.

Para compreender como se deu a luta dos movimentos de mulheres nos primeiros anos da República brasileira é de fundamental importância esclarecer o conceito de emancipação feminina presente nestes jornais. Tal noção permeia os argumentos utilizados por mulheres que conseguiram expressar seus pontos de vista em um período em que a maioria da sociedade defendia a participação da mulher de maneira limitada à esfera privada. Além disso, o estudo acerca do conceito de emancipação feminina proposto nestes jornais contribui para a melhor compreensão sobre como se deram as lutas de movimentos de mulheres no passado e que, atualmente, são a base para as reivindicações de igualdade social, civil e política de fato, e não apenas a igualdade garantida pelas instituições oficiais.

Nesta perspectiva, o artigo propõe a investigação de fontes históricas a partir de exemplares de $O$ Quinze de Novembro do Sexo Feminino e A Família a fim de compreender as nuances de argumentação construídas por suas idealizadoras no que se refere ao papel da mulher na sociedade. Como parte deste processo, é necessária a abordagem acerca de algumas questões relacionadas ao contexto histórico brasileiro do século XIX e ao desenvolvimento do movimento feminista neste período. 


\section{Entre o Império e a República: questionamentos, reivindicações e construção do movimento feminista}

No contexto das últimas décadas do século XIX, o Brasil passou por transformações sociais, econômicas, políticas e culturais que modificaram de modo significativo o perfil da sociedade brasileira. O trabalho escravo foi substituído pela mão de obra assalariada livre, o crescimento industrial deu impulso à imigração europeia, o setor de serviços cresceu e a entrada de capitais estrangeiros acelerou o processo de urbanização. Com o crescimento das cidades, ampliaram-se também as camadas médias e a vida cultural nos centros urbanos, levando à formação de uma opinião pública capaz de reivindicar a igualdade de direitos.

Em I889, um ano após a abolição da escravidão, a proclamação da República ampliou o engajamento das mulheres em favor da luta pela universalização dos direitos políticos. Embora o tema da inclusão das mulheres como cidadãs elegíveis tenha sido discutido na Assembleia Constituinte, em I89I, a Constituição foi promulgada determinando apenas que o corpo de eleitores deveria ser formado por "cidadãos alfabetizados e maiores de 2I anos" (PRADO; FRANCO 2OI2). A ausência de menção à participação das mulheres deixava ambíguo o texto constitucional, uma vez que não defendia o direito ao voto feminino, mas também não o excluía explicitamente.

Esta ambiguidade incentivou diversas mulheres a defender o alistamento eleitoral e o lançamento de candidaturas, a exemplo de Maria Augusta Meira de Vasconcelos, Isabel de Souza Matos e Isabel Dilon (id. ibid.). Tais tentativas não obtiveram sucesso, pois, de fato, a legislação foi interpretada de modo a marginalizar as mulheres politicamente. Ainda assim, as candidaturas cumpriram o papel de questionar a ordem vigente e pressionar os representantes do povo para que o novo regime não fosse apenas republicano, mas também democrático.

Neste cenário, a imprensa feminista da época se manifestou colocando em debate as condições intelectuais do corpo de eleitores da nova República, conforme pode-se observar em artigo escrito por Josephina Alvares de Azevedo e publicado no jornal A Família, em 30 de novembro de I889 (p. I):

Nossas aptidões não podem ser delimitadas pelos preconceitos de sexo, principalmente nos casos com que tenhamos de afirmar a nossa soberania pelo direito de voto. O direito de votar não pode, não deve, não é justo que tenha outra restrição além da emancipação intelectual. 
A emancipação da mulher na imprensa feminista nos primeiros anos da República no Brasil

A imprensa feminista ampliava, dessa forma, o debate sobre a permissão do voto para a população alfabetizada enfatizando a igualdade intelectual entre homens e mulheres como condição para a participação política. Este posicionamento engrossou as fileiras de partidários à causa feminista que, ao longo das primeiras décadas do século XX, foi fundamental para pressionar o governo a incluir o direito ao voto das mulheres na Constituição de I932. ${ }^{\mathrm{I}}$

O reconhecimento da opressão específica sofrida pelas mulheres e o surgimento do feminismo enquanto movimento político de contestação das relações sociais de poder tiveram no Brasil suas manifestações iniciais na primeira metade do século XIX, período que inaugura a primeira fase (ou onda) do feminismo no país, como propõe Duarte (2003).

A participação feminina em momentos históricos de ruptura evidencia a ousadia de mulheres que ansiavam pelo envolvimento com questões políticas do país. Como apresentam Prado e Franco (2012), embora fossem exceções, Bárbara de Alencar (I760-I832), Maria Quitéria de Medeiros (I792-I853) e Antonia Alves (Jovita) Feitosa (I848-I867) são exemplos de mulheres que usaram disfarces para terem aparência masculina com o intuito de lutar na Revolução Pernambucana, na Independência do Brasil e na Guerra do Paraguai, respectivamente. Mas a reivindicação predominante no decorrer do século XIX do feminismo no Brasil não esteve relacionada diretamente à participação política da maneira como buscaram implementar Bárbara, Maria Quitéria e Jovita. O acesso à educação foi tomado como principal elemento provedor da emancipação da mulher. ${ }^{2}$

No Brasil, apenas em I827 aprovou-se a Lei Geral da Educação autorizando a abertura de escolas femininas de primeiras letras e, em I879, a Lei Leôncio de Carvalho garantiu à mulher o acesso às instituições brasileiras em ensino superior (ROSEMBERG 20I2). Apontada por muitos pesquisadores como a primeira feminista do Brasil, segundo Prado e Franco (2012) e Duarte (2003), Nísia Floresta foi uma das grandes defensoras do direito das mulheres à educação e à capacitação intelectual. ${ }^{3}$

I Embora em 1927 o Estado do Rio Grande do Norte tenha se tornado pioneiro na garantia do voto feminino durante o governo de Juvenal Lamartine, em termos nacionais somente em 1932 o novo Código Eleitoral do Brasil incluiu a mulher como detentora do direito ao voto (PINTO 2003 ).

2 Em um contexto global, autoras como Teles (I993) e Pinto (2003) se referem a um período anterior ao século XIX como possível marco inicial da luta pelo direito à cidadania das mulheres. Neste sentido, a Declaração dos direitos da mulher e da cidadã, escrita por Olympes de Gouges em I79I, e a obra Reivindicações dos direitos da mulher, escrita em I792 por Mary Wollstonecraft, são exemplos de documentos que demonstram uma preocupação com a emancipação feminina (GONZÁLEZ 20IO).

3 Sua tradução livre de A Vindication of the Rights of Woman, de Mary Wollstonecraft, intitulada Direito das mulheres e injustiça dos homens (I832), tornou-se um marco do feminismo brasileiro e lhe trouxe notoriedade. 
Embora seu posicionamento em relação aos papéis ocupados pela mulher na sociedade possa ser visto nos dias de hoje como pouco transgressor, a argumentação de Nísia deve antes ser tomada como uma possível "estratégia de realidade". Isto porque a mesma acreditava que: "Cumprindo suas 'obrigações naturais', as mulheres conseguirão obter uma 'grande ascendência' sobre os homens, fazendo com que eles, ao invés de colocarem-nas em papel secundário, reconheçam o 'proveito real que podem obter dessa importante parte da humanidade"' (PRADO; FRANGO 2012, p. 207).

A proclamação da República no Brasil e o processo de formulação da Constituição em I89I foram importantes momentos para catalisar a luta pelo direito político do voto das mulheres. Embora a última década do século XIX tenha se encerrado com uma momentânea derrota da luta pelo voto feminino, este período pode ser visto em contrapartida como um momento de fortalecimento da imprensa feminista. Com ela tornou-se possível a veiculação de opiniões que questionavam algumas das relações vigentes, apresentando discursos elaborados pelas próprias mulheres e inserindo uma perspectiva de protagonismo ao "segundo sexo". Nesse sentido, a história das mulheres começa a ser, paulatinamente, contada não exclusivamente pelo viés da dominação masculina.

\section{A imprensa feminista}

De início, é necessário estabelecer o referencial utilizado para diferenciar a imprensa denominada feminista da imprensa feminina. Evelyne Sullerot (I963 apud BUITONI 2009) propõe uma divisão em dois principais planos. O primeiro deles está relacionado aos "deveres" destinados às mulheres, compreendendo as publicações que tratam de assuntos como moda, estilo, comportamento, culinária e demais temas circulares reaproveitados a cada estação do ano. A outra categoria é chamada pela autora de "direitos" e concentra as publicações que abordam a condição feminina. No século XIX a maioria das revistas com público-alvo voltado às mulheres se enquadrava no primeiro grupo, compondo a imprensa feminina. Em número mais restrito, estavam os periódicos da imprensa feminista, com foco na reivindicação dos direitos das mulheres. Vale ressaltar que os jornais A Família e O Quinze de Novembro do Sexo Feminino, objetos de estudo deste artigo, não se autointitulavam "feministas", sendo esta uma consideração resultante da análise das fontes selecionadas.

O primeiro jornal brasileiro destinado ao público feminino e produzido por mulheres foi criado em I852 por Joana Paula Manso de Noronha: o Jornal 
A emancipação da mulher na imprensa feminista nos primeiros anos da República no Brasil

das Senhoras (editado até I955), segundo Duarte (2003) e Oliveira (2009).4 No editorial do primeiro número do jornal - em diálogo com a imprensa feminina francesa ${ }^{5}$ - sua fundadora enfatizava a necessidade das mulheres buscarem instrução como meio de alcançar melhorias sociais e emancipação. Além disso, "O pioneirismo do Jornal das Senhoras, e suas colaboradoras tímidas e anônimas, representaram, ainda assim, um decisivo passo na longa trajetória das mulheres em direção à superação de seus receios e conscientização de direitos" (DUARTE 2003, p. I55).

Pouco mais de duas décadas após a criação do Jornal das Senhoras, em I873, Francisca Senhorinha Motta Diniz fundara na cidade de Campanha da Princesa, Minas Gerais, o jornal O Sexo Feminino. Para Géli Pinto (2003) e Gondin da Fonseca (I94I apud BUITONI 2009), este fora provavelmente o primeiro periódico brasileiro a engajar-se profundamente com a defesa dos interesses das mulheres. Desde seu primeiro número, a questão do acesso à educação para a população feminina aparece em destaque, como no trecho a seguir do texto de abertura do jornal: "O século XIX, século das luzes, não se findará sem que os homens se convençam de que mais da metade dos males que os oprimem é devido ao descuido que eles tem tido com a educação das mulheres" (DINIZ, O Sexo Feminino, Iํㅗ set. I873, p. I).

O Sexo Feminino contou com três fases de publicação. A primeira delas encerrou-se em I875, sendo posteriormente editado de I887 a I889, desta vez no Rio de Janeiro devido à mudança de Francisca Senhorinha para a Corte. Neste momento o jornal ganhou muito mais visibilidade, obtendo um expressivo número de tiragem e reunindo assinaturas de pessoas ilustres, como o próprio imperador d. Pedro II e a princesa Isabel (Duarte 2009). Por inspiração da proclamação da República no Brasil, o jornal altera seu nome, passando a ser 0 Quinze de Novembro do Sexo Feminino a partir de dezembro de I889 e sendo publicado até I896.

4 Dulcília Buitoni (2009) afirma que o primeiro periódico feminino brasileiro teria sido O Espelho Diamantino, criado no Rio de Janeiro em I827. Entretanto, Karine Oliveira e Constância Duarte discordam desta classificação por considerarem ser necessário aos jornais femininos não apenas a especificação do público-alvo, mas também a participação efetiva de mulheres na elaboração e produção do jornal. No texto de Buitoni encontra-se apenas a referência ao subtítulo de O Espelho Diamantino: "Periódico de política, literatura, bellas-artes, theatro, e modas dedicado as senhoras brasileiras". Informações sobre a fundação ou autoria do jornal não são apresentadas pela autora.

5 Oliveira (2009) e Buitoni (2009) apontam o inglês Lady's Mercury, fundado em I693, como o primeiro jornal feminino que se tem notícia, porém, é a imprensa francesa a principal difusora de publicações femininas nas Américas e, principalmente, no Brasil. O jornal literário foi o formato que mais obteve êxito no decorrer do século XIX, a exemplo do Journal des Dames, fundado em I759. 
O jornal A Família foi criado por Josefina Álvares de Azevedo na cidade de São Paulo em I888. No ano seguinte, passou a ser publicado no Rio de Janeiro a fim de obter maior visibilidade e permaneceu sendo editado na capital até I898. Como apontam alguns estudos (Duarte 2003; Oliveira 2009; Pinto 2003), A Família é considerada uma das publicações mais enfáticas e combativas na defesa de direitos e na participação mais ampla das mulheres na sociedade, havendo destaque para a militância no voto feminino. O texto de apresentação do jornal em sua primeira edição exemplifica o forte caráter de luta das ideias defendidas por Josefina Álvares de Azevedo, ao afirmar que:

A consciência universal dorme sobre uma grande iniquidade secular - a escravidão da mulher. Até hoje tem os homens mantido o falso e funesto princípio de nossa inferioridade. Mas nós não somos a eles inferiores porque somos suas semelhantes, embora de sexo diverso. [...] Portanto, em tudo devemos competir com os homens - no governo da família, como na direção do estado (AZEVEDO, A Família, I8 nov. I888, p. I).

Buscando um balanço em relação às características gerais da imprensa feminina no século XIX, Dulcília Buitoni (2009) destaca o grande número de jornais deste período (muitos deles, com poucas edições publicadas) e o caráter crítico destes materiais que lidavam intensamente com questões polêmicas da sociedade. A imprensa feminista era uma vertente minoritária neste contexto e as perspectivas apresentadas por este grupo podem ser encontradas em A Família e em $O$ Quinze de Novembro do Sexo Feminino, dois jornais que exerceram a defesa dos direitos e maiores liberdades das mulheres brasileiras.

Propõe-se dessa forma o trabalho com tais publicações como fontes históricas para a investigação de uma problemática: a noção de emancipação feminina, considerando a análise de exemplares que abordam de maneira significativa esta questão. Sobre a utilização de jornais e revistas como fontes na pesquisa histórica no Brasil, Tania Regina de Luca (2006) afirma que tal uso não foi recorrente de maneira sistemática até meados da década de I970. A autora realiza uma discussão acerca dos fatores que impediam a "escrita da História por meio da imprensa", caso da concepção de que os documentos utilizados nas pesquisas deveriam possuir objetividade e neutralidade, fazendo com que jornais e revistas fossem vistos como pouco adequados a este propósito. O início da alteração desse quadro se deu a partir de algumas das novas práticas historiográficas propostas pela Escola dos Annales. Trabalhos de reconhecidos pesquisadores brasileiros utilizando jornais para obtenção de diversos dados e a publicação de obras analíticas com enfoque em periódicos específi- 
A emancipação da mulher na imprensa feminista nos primeiros anos da República no Brasil

cos também são apontados por De Luca como decisivos para as mudanças que fizeram com que a produção acadêmica no Brasil, a partir de I985, recorresse mais amplamente à imprensa. ${ }^{6}$

No que se refere ao trabalho com este tipo de documentação, Tania de Luca indica aspectos aos quais o pesquisador deve estar atento para a realização da análise das fontes, tais como a caracterização de ordem material, identificando a periodicidade; a materialidade e a organização interna de conteúdos, observando a iconografia e/ou propaganda; identificação do público-alvo a que as fontes se destinam, dos colaboradores e envolvidos diretamente com as publicações. Os recursos de argumentação utilizados pelos jornais para formação de um discurso de defesa de certas causas e para formação de sua própria imagem também são aspectos de relevância.

\section{A Família: "Jornal literário dedicado à educação da mãe de família" 7}

Em novembro de I888 teve início a publicação do jornal A Família, periódico de circulação semanal, cuja proprietária e redatora era a professora Josephina Alvares de Azevedo. Conforme anunciou estrategicamente o título A Família, e o subtítulo das primeiras edições - "Dedicado à educação da mãe de família" -, o jornal era direcionado ao público feminino letrado composto pela elite aristocrática e parte das camadas médias dos centros urbanos. Contando com colaboradoras nacionais e internacionais, que dividiam de quatro a oito páginas de texto, sem iconografia, em uma mesma publicação do A Família é possível encontrar artigos de opinião pública, tradução de textos franceses relevantes para a causa feminista, narrativas em prosa, contos, poemas, seção de humor, fatos novidadeiros, atualidades, anúncios e um profundo diálogo com outros jornais da época, favoráveis e contrários às matérias publicadas por Josephina Alvares de Azevedo.

6 A autora destaca um texto de Ana Maria de Almeida Camargo ("A imprensa periódica como fonte para a História do Brasil", I97I) por ter ido "além das recomendações metodológicas próprias dos ensaios teóricos e avaliou como os desafios [de utilização da imprensa como fonte histórica] estavam sendo enfrentados na prática" (DE LUCA 2006, p. II7). O bravo matutino (I980), de Maria Helena Capelato e Maria Ligia Prado, também é mencionado como uma importante obra para este movimento, tendo em vista que o jornal $O$ Estado de $S$. Paulo é tomado como única fonte de investigação e análise crítica do trabalho.

7 Subtítulo da primeira edição do jornal. 
Quanto ao alcance do jornal, pode-se calcular pelo impacto que causou em sua época, registrado pelas diversas menções feitas por outros periódicos. Jornais como: Diário Popular, Diário Paulistano, Diário do Commercio, Gazeta da Bahia, Constitucional, Província do Pará, entre outros, se posicionavam ora apoiando a proposta de Josephina, ora tentando influenciar as publicações por meio da crítica direta, como fez o Província de São Paulo ao comentar a epígrafe do A Família, afirmando que

O artigo da redação tem por epígrafe estas palavras de Victor Hugo: "Veneremos a mulher! Santifiquemo-la e glorifiquemo-la!" Inteiramente de acordo, exma senhora. Permita-nos, porém, que humildemente lhe digamos que a mulher para ser venerada, glorificada e, sobretudo santificada, não deve competir com o homem na "direção do Estado" e em muitas coisas mais, como v. V. Exc. Sustenta (apud OLIVEIRA 2009, p. 25).

De acordo com Karine da Rocha Oliveira (2009), o objetivo do jornal seria despertar a consciência das mães para o papel da mulher na vida pública intelectual, profissional e política, ocupando espaços tipicamente masculinos, a exemplo das mulheres francesas e inglesas. Para isso, defendia Josephina, as mulheres deveriam se unir, se instruir, participar ativamente da política, da economia, da medicina e das leis. Dessa forma, é possível perceber que frequentemente o conceito de emancipação feminina aparece no jornal A Família relacionado ao direito à educação, ao campo profissional e a participação política.

Tomando como exemplo para análise a edição de número 40, publicada em 30 de novembro de I889, poucos dias após a proclamação da República, pode-se identificar algumas características comuns a todas as edições do jornal. Frequentemente abordado na primeira página, sob o título A Família e aspecto de editorial, os textos assinados por Josephina tocam em assuntos conflitantes, quase sempre relacionados ao conceito de emancipação feminina. Nesta edição, por exemplo, a autora inicia seu texto com a seguinte pergunta para a então nova República brasileira: "No fundo escuro e triste do quadro de provações a que votaram a mulher na sociedade, brilhará, com a fulgente aurora da República Brasileira, a luz deslumbradora da nossa emancipação? [...] Qual o destino que lhe reservam no conflito da vida nacional?” (AZEVEDO, A Família, 30 nov. I889, p. I).

A reivindicação do jornal é a de que junto com o processo de extinção da monarquia, velhas tradições fossem superadas e a democratização no espaço público privilegiasse a igualdade entre homens e mulheres. Neste sentido, a 
A emancipação da mulher na imprensa feminista nos primeiros anos da República no Brasil

condição básica a ser considerada, conforme Josephina, seria a capacidade intelectual. Ainda na edição de número 40, a escritora defende a capacidade intelectual da mulher em dois momentos: o primeiro ao mencionar dois colégios que visitou na Bahia, administrados por mulheres, e que "são dois dos melhores estabelecimentos de educação [...] guiados pelos melhores métodos de instrução e servidos por professoras inteligentíssimas" (id. ibid., p. 2); o segundo, ao destacar na seção "novidades" a formação em nível superior de duas mulheres, Antonieta Dias que obteve o título de doutora pela Faculdade de Medicina do Rio de Janeiro, e Maria Augusta Lins Meira de Vasconcellos que se graduou em direito pela Faculdade do Recife. As notícias de mulheres que alcançavam formação em nível superior eram com frequência abordadas pelo jornal, desde a sua primeira edição.

$\mathrm{O}$ aspecto da capacidade intelectual está voltado tanto para o âmbito privado, onde a mulher tem importante papel como administradora do lar e educadora dos filhos, como para o campo educacional e profissional, espaços que, à época, eram majoritariamente masculinos. Ainda na seção "novidades" da mesma edição de número 40 , sobre a emancipação da mulher no campo educacional e profissional, Josephina destaca que: "provando por todos os dotes intelectuais a competência da mulher no concurso das profissões, de par com os homens, a formatura da dra. Antonieta Dias vem reforçar tacitamente o protesto mais veemente contra as opiniões contrárias a nossa emancipação" (id. ibid., p. 6). E no que se refere à Maria Augusta Lins Meira de Vasconcellos, "resta agora saber se uma senhora que se habilita para os cargos da advocacia, que recebe um grau pela Faculdade do Estado e se mostra capaz de concorrer nas funções públicas para o bem dos seus constituintes, deve estar sujeita aos caprichos dos que não queiram reconhecê-la, como já se fez em um júri de Pernambuco" (id. ibid.).

Além de englobar os aspectos da capacidade intelectual voltados para o preparo da mulher no campo educacional e profissional, a emancipação feminina não poderia estar completa sem a participação no sistema representativo político brasileiro. Josephina argumentava que "é necessário que a mulher, também, como ser pensante, como parte importantíssima da grande alma nacional, como uma individualidade emancipada, seja admitida ao pleito em que vão ser postos em jogo os destinos da Pátria” (id. ibid., p. I). E reitera que as mulheres querem "o direito de intervir nas eleições, de eleger e ser eleitas, como os homens, em igualdade de condições" (id. ibid.).

Considerando as lutas que os movimentos de mulheres travaram ao longo da história do Brasil, deve-se reconhecer ao jornal A Família papel de destaque 
na luta pela superação da ideia de inferioridade biológica ou intelectual das mulheres, ideias defendidas até meados do século XIX. Além disso, é clara a agência social da redatora Josephina Alvarez de Azevedo em favor da diminuição dos preconceitos e estereótipos sobre a atuação das mulheres no campo profissional e pela universalização dos direitos políticos, que somente 44 anos após a publicação da primeira edição do A Família seriam garantidos oficialmente por meio da Constituição de I932.

\section{Iv. O Quinze de Novembro do Sexo Feminino: “É por intermédio da mulher que a natureza escreve no coração do homem" ${ }^{8}$}

Como brevemente apresentado na seção sobre a imprensa feminista, O Quinze de Novembro do Sexo Feminino corresponde a terceira e última etapa das publicações de autoria de Francisca Senhorinha Motta Diniz. O subtítulo do jornal indica sua periodicidade média, "Periódico quinzenal, literário, recreativo e noticioso - especialmente dedicado aos interesses da mulher", e sua primeira edição é datada de I5 de dezembro de I889, correspondendo ao número I2, ano III, em continuidade direta à segunda fase de "O Sexo Feminino".

A fundadora e redatora de $O$ Quinze de Novembro do Sexo Feminino desde muito jovem teve contato com o universo do trabalho a partir do magistério, realizando viagens ao interior de Minas Gerais para atuar como professora (NASCIMENTO 2004). É possível que o contato com diferentes ambientes no exercício de sua profissão tenha sido um elemento importante para sua formação não apenas intelectual, mas também política, sendo tal intercâmbio potencializado com a mudança para a Corte em I875. Francisca Senhorinha é apontada por alguns autores como uma das primeiras feministas do Brasil (GODIN DA FONSEGA I94I apud NASCIMENTO 2004, p. 23). Seu jornal contava ainda com a colaboração de várias mulheres no envio de textos na seção de poesias, prosas, variedades e assuntos políticos, havendo algumas exceções para publicações feitas por homens.

Em termos da organização interna do jornal, cada publicação possui o total de quatro páginas, não havendo iconografia. Os conteúdos presentes nas edições consideradas na análise se relacionam a textos literários, como

8 Frase de autoria de Aimr' Martín, utilizada como epígrafe do jornal. 
A emancipação da mulher na imprensa feminista nos primeiros anos da República no Brasil

folhetins, poesias e variedades; notícias envolvendo realizações feitas por mulheres e descobertas científicas da época; anúncios de serviços prestados por médicos, professoras, fotógrafos, músicos e também por estabelecimentos, como lojas de moda, entre outros. A "Escola Doméstica" do Colégio Santa Isabel (destinada a meninas pobres, órfãs, com idade entre quatro e quinze anos), fundada por Francisca Senhorinha e suas filhas, tem longo espaço de divulgação em alguns números. O conteúdo de maior interesse para a análise se refere a seções destinadas à discussão da emancipação da mulher e da educação para o sexo feminino, de autoria da proprietária do jornal.

O público-alvo de $O$ Quinze de Novembro do Sexo Feminino era, em primeiro plano, as mulheres alfabetizadas com acesso à escolarização. $\mathrm{Na}$ época, tal perfil indicava um recorte direcionado às classes sociais mais abastadas, mas não é possível afirmar que o jornal destinava-se inicialmente apenas a mulheres que já tinham interesses por temas voltados à educação ou à luta por direitos. Isto porque a publicação manteve seções que habitualmente são mais características da imprensa feminina, caso da presença do folhetim A Diva Isabella e da seção "Charadas", recorrentes em todos os números analisados. A parte de Literatura/Variedades apresentava textos de variados estilos (poesia, conto, romance, receitas de culinária) sem caráter político ou engajado. Este tipo de recorrência pode ser vista como uma estratégia de não delimitação de seu público, que poderia interessar-se pela publicação a partir do que ela oferecia de mais corriqueiro e aos poucos se envolver com as seções que a diferenciavam da grande imprensa feminina, como a "A racional emancipação da mulher" e "Sciencia".

A fim de identificar um exemplar do jornal que fosse representativo em relação à investigação da emancipação da mulher, foi lida a seção "A racional emancipação da mulher" de todas as edições consideradas na análise. ${ }^{9}$ Tal espaço no periódico, com exceção do primeiro número, é o primeiro texto do jornal e possui em geral caráter persuasivo. Por não contar com a assinatura de nenhuma colaboradora, atribui-se em sua totalidade a autoria dos textos desta seção à redatora e proprietária do jornal.

O elemento de maior destaque e que foi verificado em praticamente todos os números diz respeito à necessidade de igualdade de direitos. Ou

9 Os números consultados foram disponibilizados pelo website da Hemeroteca Digital Brasileira. São estes: do n. I2 ao I4; do n. I8 ao 2I e o n. 23 (apenas o primeiro número citado corresponde ao ano de I889. Os demais foram publicados em I890). 
seja, para $O$ Quinze de Novembro do Sexo Feminino a emancipação da mulher se tornaria uma realidade no Brasil apenas quando fosse atingida a igualdade de direitos entre os sexos feminino e masculino. Os representantes do "sexo forte" deveriam formular leis que contemplassem de maneira igualitária toda a população, segundo Francisca Senhorinha. Em diferentes números do jornal estão presentes referências diretas a esta questão, afirmando-se, por exemplo, que: "hoje, dizemos, a mulher quer ver o Estado distribuir igualdade de leis". Os demais pontos apresentados como complementares a esta noção de igualdade de direitos dizem respeito à participação feminina nas eleições e ao acesso à educação de maneira ampliada.

O exemplar que de forma mais interessante sintetizou tais reivindicações recorrentes no jornal foi publicado em 06 de abril de I89o (n. I4, ano III). A parte inicial da seção "A racional emancipação da mulher" apresenta a crença de que mudanças de ordem estrutural na sociedade poderiam ocorrer visando o "pleno desenvolvimento a sua natureza física, moral e intelectual [da mulher]" (DINIZ o6 abr. I890, p. I). A autora prossegue afirmando que as limitações impostas à atuação da mulher na sociedade são comparadas a uma condição de semiescravidão, que mutilaria aspectos de sua personalidade. O trecho a seguir condensa um dos principais pontos defendidos pelo jornal: "A emancipação da mulher pelo estudo é o facho luminoso que pode dissipar-lhe as trevas pela verdade em que deve viver e que a levará ao tempo augusto da ciência, de bem viver da sociedade civilizadora" (id. ibid., p. I). A ideia de uma "emancipação racional" recorrente em todo o jornal passa pela valorização da ciência e da ideia de civilização existente na época. Um último aspecto a ser comentado como elemento que compõe a ideia de emancipação da mulher no jornal se refere a sua participação política a partir do voto: "Nós as Brasileiras, as Italianas, Francesas e mais senhoras de diversas nacionalidades não pedimos o direito de votar com a restrição com que o fizeram às senhoras inglesas, mas com o direito de cidadãs republicanas" (id. ibid., p. 2).

A análise realizada possibilita a identificação da igualdade entre homens e mulheres como o elemento mais característico e central da emancipação feminina na concepção sustentada por O Quinze de Novembro do Sexo Feminino. Tal igualdade é defendida como uma espécie de lei natural, concebida a partir de diferentes dimensões. A participação das mulheres no campo político com o direito ao voto e, em maior ênfase, no acesso à escolarização que garantiria formação intelectual e profissional, tornariam possíveis desdobramentos decorrentes da emancipação do sexo feminino. 


\section{v. Possíveis delineamentos sobre o conceito de emancipação feminina}

De modo geral, é possível indicar algumas aproximações e distanciamentos entre as opiniões veiculadas nos jornais estudados. Em termos de semelhança, os debates realizados por Josephina Azevedo e Francisca Diniz compartilhavam o mesmo público-alvo e apresentavam em seus discursos influências bastante significativas de ideais positivistas. A noção de racionalidade e as descobertas realizadas em diversos campos da ciência são valorizadas em $O$ Quinze de Novembro do Sexo Feminino, compondo uma seção específica do jornal ("Sciencia"), por exemplo. Em A Família os feitos de natureza científica não possuem o mesmo destaque. Entretanto, existe o apego e a recorrência à ideia de manutenção da ordem na argumentação de Josephina.

Outros aspectos que aproximam as duas publicações se referem às justificativas apresentadas para fundamentar a luta pela emancipação das mulheres. Em ambos os jornais é interessante citar que não se verificou a negação acerca do exercício da maternidade e da formação da família, assumindo as mulheres, neste contexto, a responsabilidade pela educação de sua prole, o que também poderia ser visto como um benefício à própria pátria. A instrução seria concebida enquanto possibilidade de melhoramento da maternidade, representando em instância maior um ganho relativo a toda a humanidade. Em ambos os jornais é defendida a apropriação de novos espaços por parte das mulheres, como a entrada no mercado de trabalho a partir de formação profissionalizante. Todavia, o espaço privado não deveria ser perdido ou recusado, tendo em vista que se acreditava na incapacidade masculina de lidar com a esfera doméstica.

As diferenças mais acentuadas entre as propostas de A Família e $O$ Quinze de Novembro do Sexo Feminino estão relacionadas à forma de dialogar com os homens. Francisca Diniz dá ênfase à necessidade de que a dominação masculina ceda espaço à atuação das mulheres. Por esta lógica, é de responsabilidade e preocupação dos homens a reelaboração de leis mais justas em relação ao sexo feminino, assim como o fim da negligência em se tratando da falta de escolarização das mulheres. Sua fala também se direciona para a realização de ações por parte do público feminino, mas é notável o investimento no diálogo com o chamado "sexo forte". A argumentação de Josephina Azevedo encaminha-se por meio de outras estratégias. Percebe-se a predominância de um tom muito mais combativo e, em alguns casos, incompatível com a postura de reivindicar concessões. Neste caso, a ênfase se direciona para a atuação direta das mulheres, que deveriam intervir a fim de promover as condições necessárias para a ascensão na sociedade. 
Assim, como seria possível compreender o conceito de emancipação das mulheres formulado na última década do século XIX a partir dos documentos consultados? O resultado da análise indicou que a concepção de emancipação feminina nos dois jornais enfatizou a capacidade intelectual das mulheres a fim de que tenham maior acesso ao campo profissional e à participação política, em igualdade com os homens. Porém, somente o jornal A Família enfatiza como condição necessária à emancipação a tríade a seguir: a universalização do direito à educação, a inserção no campo profissional e o direito à participação política. Por outro lado, O Quinze de Novembro do Sexo Feminino confere maior peso à formação educacional como meio de emancipar e tornar mais igualitária a relação entre os direitos de homens e mulheres.

Considerando suas diferenças e similitudes, ambos os jornais se tornaram instrumento de reivindicação pela maior participação feminina na sociedade. O fortalecimento da imprensa feminista se reverteu em via de expressão e de difusão de um discurso elaborado pelas próprias mulheres. Como parte da conjuntura política do Brasil no final do século XIX, estes jornais e suas autoras reuniram elementos motivadores para o engajamento político das mulheres, contribuindo para o acúmulo de experiência e de maturidade para as novas reivindicações e lutas do porvir.

\section{Referências bibliográficas}

AZEVEDO, J. A. A família. A Família, São Paulo, I8 nov. I888. p. I. A família. A Família, São Paulo, 30 nov. I889. p. I.

BUITONI, D. H. S. Mulher de papel: a representação da mulher pela imprensa feminina brasileira. São Paulo: Summus, 2009. 240 p.

DE LUGA, T. R. História dos, nos e por meio dos periódicos. In: PINSKY, G. Fontes históricas. 2. ed. São Paulo: Contexto, 2006, pp. III-53.

DINIZ, F. S. M. A educação da mulher. O Sexo Feminino, Campanha, MG, o7 set. I873. p. I.

- A racional emancipação da mulher. O Quinze de Novembro do Sexo Feminino, Rio de Janeiro, 06 abr. I890, pp. I-2.

DUARTE, G. Feminismo e literatura no Brasil. Estudos Avançados, v. I7, n. 49, 2003, pp. I5I-73.

GONZÁLEZ, A. I. A. Os teóricos socialistas e questão da mulher. In: As origens e a comemoração do dia internacional das mulheres. São Paulo: Expressão Popular, 2010, pp. 49-54. 
A emancipação da mulher na imprensa feminista nos primeiros anos da República no Brasil

NASGIMENTO, G. V. O sexo feminino em campanha pela emancipação da mulher (1873/1874). 2004. I06 f. Dissertação (Mestrado em História da Educação). Faculdade de Educação, Universidade Federal de Minas Gerais, Belo Horizonte, 2004.

OLIVEIRA, K. R. Josefina Álvares de Azevedo: a voz feminina no século XIX através das páginas do jornal A Família. Disponível em: <http://www.bn.br/ portal/arquivos/pdf/Karine_da_Rocha.pdf>. Acesso em: I6 mar. 2014 .

PINTO, G. R. J. Uma história do feminismo no Brasil. São Paulo: Fundação Perseu Abramo, 2003. II9 p. (Coleção História do Povo Brasileiro).

PRADO, M. L.; FRANCO, S. S. Participação feminina no debate público brasileiro. In: PINSKY, G. B.; PEDRO, J. M. (Orgs.). Nova história das mulheres no Brasil. São Paulo: Contexto, 2012, pp. I94-2I7.

ROSEMBERG, F. Mulheres educadas e a educação de mulheres. In: PINSKY, C. B.; PEDRO, J. M. (Orgs.). Nova história das mulheres no Brasil. São Paulo: Contexto, 20I2, pp. 333-59.

TELES, M. A. A. Breve história do feminismo no Brasil. São Paulo: Brasiliense, I993. (Coleção Tudo é História).

\footnotetext{
-

Marta de Souza Rodrigues - Graduanda em História pela Universidade de São Paulo.

martadesouza@gmail.com

Artur Alves da Silva - Graduando em História pela Universidade de São Paulo.

artur.alves.silva@gmail.com
} 